\title{
Oglindire arhetipală și consistență ontologică în Empireul lui Heliade- Rădulescu
}

Drd. VLAD Ana-Maria

Universitatea „Dunărea de Jos” din Galați

\begin{abstract}
Anatolia in terms of descriptive and aesthetic form gives an oscillation between the horizon of character consciousness through a remodeled structure of the tongue and the demiurgic image to which all the teluric is subordinated.

The creepy condition of evil makes it easier to portray the portraits of the characters through the coexistence within the work of the many literary motifs among which we mention: hatred, foolish pride, selfishness, envy. The act of fertile denial is questioned at the textual level by the semantic intensity that occupies a significant weighting, emphasizing linguistic anxiety canonization in some statements in Anatolia. This emotional crescendo outlines the painting of sensitivity focused on the technique of counterpoint and that of detail marked on semantic, stylistic and symbolic level by reference to biblical references. The pursued approaches are the incoherence, the expression and the expressivity that schematically outlines the cosmological model in an antinomic context of human duality.
\end{abstract}

Keywords: archetypal, ontological consistency, anxiety of canonization, synchronism, counterpoint technique

Când discutăm despre creația literară a lui Heliade Rădulesu identificăm două faze: prima prerevoluționară de orientare romantică cu rezultate pozitive în plan cultural dar care se finalizează undeva în preajma anului 1840, iar cea de-a doua urmează anului anterior menționat fiind una plină de obscuritate, de neclarități în majoritatea domeniilor din viața sa.

Aceste ipostaze confirmă dualitatea aceleeași individualități dificil de împăcat. Acest scriitor controversat este o personalitate artistic contradictorie ce poate fi deslușită prin prisma vocilor antinomice din interiorul scriitorului. Prin delimitarea celor două constatăm că până în 1840 Heliade Rădulescu are ca scrieri de forță : Culegere de proză și poezie( 1836) și Căderea dracilor (1840). Opere cu valoare simbolică ar fi: Serafimul și heruvinul, Visul , O noapte pe ruinele Târgoviștei .

După 1840 activitatea lui Heliade se concretizează spre delimitarea și identificarea sinelui, interiorității prin raportare la Divinitate, Logos astfel că traduce Biblia din limba greacă în jurul anului 1858 alături de sinteze de 
recrutare religioasă, politică, filozofică sub un titlu reprezentativ : Biblicele plănuind să înfăptuiască o operă epopeică creștină, care să trateze începutul originar ( geneza) și având ca finalitate Apocalipsa, organizată în douăzeci de cânturi - Anatolida sau omul și forțele. Au văzut lumina tiparului doar 5 cânturi din acest vast proiect: Tohu-Bohu, Imnul creațiunii, Viața sau androginul, Arborele științei și Moartea sau frații. Cu perspective biblică, scriitorul direcționează viziunea unui tablou cosmic monumental reprezentării genezei intregului univers. $\mathrm{O}$ altă creație literară amplă o reprezintă lucrarea intitulată Umanitatea , un poem cu patru direcții fundamentale : Biblice, Evanghelice, Omul social, Omul individual.

Conform Dicționarului Explicativ al Limbii Române empireu este un substantiv neutru, iar în mitologia greco- romană reprezintă partea cea mai de sus a bolții cerești unde se afla locașul zeilor și al focului etern. 2 sn Reședința zeilor. 3 sn (Liv; pex) Locașul celor fericiți, cer.

Tematica poemului reunește în totalitatea structurii componente ca teme fundamentale ce stau la baza Genezei, cum ar fi : Improbabilul, Infinitul Absolut, Necunoscutul, Idealitate. Ca și motive subsidiare amintim fortuna labilis, vanitas vanitatum et omnia vanitas, fugit irreparabile tempus. Poemul accentuează două perspective către latura interioară a Universului și cea a Spiritului. Nevoia de aspirație spre Infinit accentuează infinitudinea ca fiind net superioară finitudinii deoarece ea reprezintă includerea în profunzimea Lumii, în teluric unde identificăm viziunile esențialului. Clasarea limbajului poetic ca formă de manifestare a limbii deplasând centrul de interes de la imaginea externă a existenței spre nucleul semnificațiilor, către esență. Starea omenească a lui Satan simte golul unei disperări: „Cu tremur şi teroare să stăm pe loc, cu frică, / La toți atenţiune! Căzutul e Satan! /Satan! răsună cerul, satan! se nalţă, pică / Satan! din sferă-n sferă, şi-n haos urlă - AN!!!/ Cu mult este mai mare căderea spirituală, / Şi nu pot fi cuvinte a se asemăna/ Cu oricare cădere ce e materială,/ E mică-asemănare concret a se-arăta ./ Când aste întunerici de lumi nenumărate, “

„Pământul era pustiu și gol “ - expresie din limba ebraică tohu wa- bohu (pustiu și gol) este alcătuită din două substantive comune, de genul neutru, numărul singular, în raport de coordonare prin utilizarea conjuncției simple coordonatoare copulative "și “. Aceste cuvinte pot avea atât sens de bază propriu și secundar alături de cel de bază și figurat. De reținut sunt și derivatele cu sufixe "pustietate " și "goliciune “ cu valoare simbolică conotativă ce derivă din contextual metaforic al operei în discuție: , Zdrobiți abia demonii sentorc, îşi cată loc./ Şi ce loc să-şi mai afle? în locul de durere,/ În locul din afară şi 
unde nu ajung / Nici pace, nici repaos, nici semne de tăcere:/ Exotic întuneric şeternul suspin lung?/ Când s-ar lua unime în loc de măsurare/ O rază de la soare şi până la pământ,/ D-aci până la ceruri e mare depărtare!/ Unimi d-astă măsură nenumărate sânt./ Sau cât este din centrul al centrelor tăriei/ Şi până peste polul şi cel mai depărtat,/ De şapte ori atâta principiul fericirii A-mpins răul din ceruri damnării rezervat. “

Cel dintâi cuvânt tohu simbolizează ," nimic “, ,gol “ ( Ieremia 4: 23) sau "pustiu “ (Iov 6 :18). Cuvântul semnifică „,deșertăciunea “ idolilor ( „lucruri de nimic “ , Cornilescu), (1 Samuel 12:21) sau lipsa de importanță ( „o nimica , Cornilescu) a popoarelor în ochii lui Dumnezeu ( Isaia 40:17), pledoarie goală (Isaia 59.4, RVS „ lucruri deșarte “ , Cornilescu) Cuvântul următor bohu îl identificăm pe tot parcursul Bibliei, ca avînd valoarea de "pustiire “ și " nimicire “ ca rezultata al judecății Domnului (Isaia 34:14), ( Ieremia 4:23)

Tohu wa-bohu se referă din punct de vedere al creației la starea materiei înainte de ordinea adusă de Cuvînt, de Logos, de Verb. Configurarea poetică a Anatolidei este de sorginte transempirică prin manifestarea simbolurilor și metaforelor prevalente. Angoasa de la suprafață pare a fi înlocuită de o neliniște autentică. Starea dezorientată a Finței umane de a se trezi deodată prăbușită într-o existență abandonată de Dumnezeu, reprezintă creuzetul inegalabilelor angoase la nivelul conștiinței vinovate: „,In ceartă elementele, cutremur în tărie,/ $\mathrm{N}$-ar face-atâta uiet ca-ast zvon spiritual./Ca soarele de mare, mai mare între stele /Şi stinşi d-a lor lumină ca Urius, Titan,/Aşa cad legioane de spirite rebele,/Moloh, Baal, Asmode, Dagon, Rimnon, Satan./Cad repezi nouă zile; căderea se-ndesează, / Din regiune-ntr-alta mai repezi vâjâiesc,/Se-ntoarce fiecare spre ceruri, să mai vază, / Şi trăsnete-nmulţite din urmă îi ajung. "

Această criză a limbajului marcat prin versurile anterioare aduc un plus de clarificare asupra faptului că are ca incipit motive duhovnicești și nu pătrunzătoare, iar nu trebuința realizării unor efecte stilistice noi. Nu existența spirituală zbuciumată a primilor oamenilor este învechită, depășită, ci limbajul s-a demodat. Dramatismul sinelui dual, sfâșierea unei conștiințe în găsirea „echilibrului antitezeler," pentru concilierea antinomiilor, vocile antitetice ale scriitorului însuși- toate acestea reies din creația sa literară. Heliade este un idealist, atras de schimbările realului, meditând la conceptual actului social, cultural etc .Din punct de vedere cultural realizările lui capătă o turnură simbolică, având o valoare în raport cu poziția sa raportată la realitățile istorice în cadrul umanității . Sub eticheta individualității sale duale, rezonanța creativă oscilează între satiric și epopeic, între grotesc și măreț în propozițiile, frazele cu o povară incisivă: „, Aşa munţii de flăcări, dup-astă-anomalie/În flisv plesnesc, 
se nalţă, iar cad şi iar plesnesc./S-alină-apoi tumultul şi nu mai e vedere,/Profund, mare-ntuneric în mijlocul de foc,/Vârteje de fum negru rotează în tăcere;/Zdrobiţi abia demonii se-ntorc, îşi cată loc./Şi ce loc să-şi mai afle?/în locul de durere,/În locul din afară şi unde nu ajung/Nici pace, nici repaos, nici semne de tăcere:/Exotic întuneric ş-eternul suspin lung?/Când s-ar lua unime în loc de măsurare/O rază de la soare şi până la pământ. “

O direcție de interpretare ne-o oferă Tudor Vianu afirmând că ", originalitatea cea mai izbitoare a lui Heliade trebuie căutată în conformitate cu temperamental lui , în expresia sentimentelor de indignare și revolă. Anatolida este metafora simbolică a opiniei lui Heliade despre rolul creației în oglindirea lumii. Cîntul I reprezintă un discurs lung al introducerii în Geneza Pământului, unde este relatat sensul istoriei ca manifestarea determinării umane. Limbajul este interpretat de Heliade într-unul în care predomină elemente și denumiri biblice : "Şi unde se dezvoltă virtuţile florali/Acolo unde-adie zefirul de clemenţă/Prin arborii ştiinței ce Domnul! Domn! Şoptesc/În quietutea naltă damor, de inocenţă,/ La râuri de viaţă ce Domn! iar murmuiesc ,"sau Răpiți în adorare, de Domnul însuflați./Ființe de simțire, cu totul de vedere,/Contemplă în mirare p-eternul Iehova/În marele panhymniu, în sfânta preveghere/Întreg nemărginitul răsună: Osana!... În sânu-eternității, de angeli nevăzut,/Etern era şi Fiul, cu Pater d-o fiinţă,.Ca un moştean al gloriei, ca Verb şi creator,/Puteri, virtuţi într-însul să se identifice.../Atenţi în tot amorul, ascultă, se supun/Văd toți pe Fiul gloriei 1-a Patrelui său dreaptă/Şi cunoscut se face Cuvântul peste tot;.../Se-ntrec să se închine la Marele Cuvânt,/Prin el să se-ntregească în toată-a lor fiinţă/Şi-ntr-însele să cheme al lui coborământ/... Pe dânsul se aşează Divinul Verb şi Fiu " din Cintul I .

Limbajul este în contrast cu cel obișnuit, comun, deoarece este unul de factură simbolică, care evocă valorile primordiale ale omului și lumii. În viziunea poetului conexiunea dintre apelativ și creatură, făptură este una misterioasă. În opera supusă studiului, cel dintâi act al omului, aproximativ creator este identificat ca fiind acela al menționării Cosmosului în antiteză cu prăbușirea din Eden ce are ca și correspondent în istorie omiterea apelativului și implicit a însemnătății lui. Acestora putem atribui ideea lui Heliade din Deascrierea Europei după tratatul de la Paris:, pierzând lucrurile am pierdut și adevărata însemnătate a lucrurilor. " - "Plumb e uşurinţa şi cerul se desface;/Cad rebelii-n spaţiu şi vâjâie căzând,/Haos, abis mare-i aşteaptă căscând/Pică şi se schimbă pe cât trec din cer/Capete de angeli, de demoni picioare,/Aripă cerească una se mai vede,/Alta infernală la valennegreşte,/Monstru la alți capul în abis precede/Tălpile, lumină în cer mai 
luceşte./Neagră, fumegândă acum sunt volvoare,/Nume, suvenire din ceruri le pier.

Se-nchide empireul. “

Evident este faptul că I.Heliade Rădulescu utilizează în poemul menționat o categorie diversificată de registre afective și stilistice. Întâlnim elementele vorbirii directe ( dialog "Şi pacea le anunţă prea blândul Gabriel./[?Cu tremur şi teroare să stăm pe loc, cu frică,/La toţi atenţiune! “ ; monolog: „Şi ce loc să-şi mai afle? în locul de durere,/În locul din afară şi unde nu ajung/Nici pace, nici repaos, nici semne de tăcere:/ Exotic întuneric ş-eternul suspin lung?") alături de cele narative care accentuează descrierea evocatoare și plastică.

Sentimentul iubirii în viziunea lui Heliade reprezintă de fapt o stare de regres ontologic în care diverse stări afective se manifestă cum ar fi: încântarea și desfătarea , tristețea profundă, dezamăgirea. Toate acestea se întorc impotriva ființei umane, accentuând lipsa de repere, de resorturi ferme într-o lume ce-l izolează pe care o percepe ca fiind înstrăinată, deoarece omul, poetul simte acum un fel de degringoladă a trăirilor, neputând distinge provocarea și justificarea senzațiilor, a percepțiilor existente ca intr-un halou. În Anatolida, Heliade Rădulescu integrează forme populare, fonetisme arhaice, regionalisme alături de alte elemente specifice oralității pentru a contura o viziune și o atmosferă specifică: „, Arhangelul răsuflă, resaltă-n el simţirea,/Se-ncântă d-a sa filie întâiul duh sperjur./Se înamoră; ea îl răpeşte,/Şi mii de angeli o numesc sor,/La toţi ea râde, ascuns fior/Pe toţi petrece. La toţi clipeşte,/Pe toţi provoacă, la toţi se-ntinde,/Cu toţi e dulce, ochii-i vorbesc;/Şi cap, şi inimi la toţi aprinde,/Ard de plăcere, tremur, doresc/Ce mare şi teribilă la angeli încercare! “

Poezia se învață ca orice techne (gr. meșteșug, iscusință, artă, știință aplicată) conclude Heliade, ea exprimând un sistem lingvistic și trăsăturile de bază ale acestuia ce necesită comprehensiune. Scriitorul prezintă în lucrarea Regulile sau gramatica poeziei: „Poezia își are limba ei ca și toate celelalte științe și meșteșuguri, și, ca să o înțelegi, trebuie sa o înveți precum se învață toate limbile [...]“ (apud Marino, 1968: 318). Relația univocă poezie - cod lingvistic are la bază după Paul Cornea, trei elemente fundamentale: „intuiția orfică a unei realități spirituale disimulată îndărătul aparențelor; un vocabular puternic, în parte de invenție personală, conținând un mare număr de abstracțiuni (deci capabil să denumească un vast nomenclator conceptual); în fine, densificarea câmpului semantic printr-o rostire secționată, frustă, lăsată dinadins în nedeterminare, făcută complice cu tăcerea, transformată în mister“ (1980: 28). Heliade Rădulescu este frământat de puritatea liricii, de tot ce este sacru în ea. 
Paul Cornea așează în prim plan idea de amânare, de suprimare a prezentării unei acțiuni sau unui obiect, unde această sincopă a limbajului va avea drept finalitate o multitudine de sensuri posibile: „Când toate s-ar exmulge din marea concentrare,/Ieşind din a lor axe, şi nu s-ar mai ținea,/S-ar precipita-n spaţiu spre-eterna lor pierzare/Şi una peste alta zdrobindu-se-ar cădea./Ast uiet ce ar face totala-anomalie,/Amestecul, ciocnirea, zgomult material,/În ceartă elementele, cutremur în tărie,/N-ar face-atâta uiet ca-ast zvon spiritual. “

Menţionăm din acest punct de vedere opinia lui Adrian Marino : „, marile sinteze de la începutul veacului (al XIX-lea, n. n.), istorice și sociologice, vor sublinia cu putere relația literatură-religie. [...] O puternică romantizare a creștinismului se constată și în literatura germana, italiana etc. Treptat, această fervoare se convertește sau se „hibridizează cu estetismul“ (1992: 174).

În Biblice și chiar în Suvenirele și impresiile unui proscris, întâlnim o inițiere în illo tempore prin utilizarea unui cod lingvistic, a unui ",idiom-simbol“. Ideeea centrală o reprezintă strădania irealizabilă a unei „limbi adamice“, în acord cu ideologia "tare“ a unei epoci în prelungirea Iluminismului, care prescria ca fundament gnoseologic enunțarea exclusiv a adevărului. „Căci, se credea, dacă nu ar putea spune minciuni, dacă n-ar putea ignora voit sau nu adevărul, oamenii s-ar înțelege perfect între ei“ (1992: 92), afirma, cu subtilă ironie, Andrei Cornea.

Idealul mesianic domină întreg textul operei, astfel că realul este descries prin termeni ce reprezintă Absolutul , indici ai unei splendori depline: ," Acolo este tronul divinei providențe,/Pe mii de miriade de repezi cherubimi./Cerească armonie organe mii răsună;/Poeții-eternitătii, serafi întraripați,/Sub degete d-auzuri vii arpele înstrună,/Răpiţi în adorare,de Domnul însuflați/Ființe de simţire, cu totul de vedere,/Contemplă în mirare peternul Iehova,/În marele panhymniu, în sfânta preveghere/Întreg nemărginitul răsună: Osana! " Autorul Anatolidei este preocupat de lupta cu forțele tenebrelor din punct de vedere spiritual. Aici întâlnim crâmpeie de profetism mundan și transcedental.

Afirmația lui Eugen Negrici, „Heliade e mai tânar și, prin asta, mai modern decât serii întregi de scriitori timorați de tradiție. Si cum să nu fie așa când în epoca sa, ca în spațiul edenic al primilor oameni, lipsește sentimentul ridicolului: tinerii fac jurăminte romanțioase în biserică pentru a schimba soarta țării, cred în utopii, lansează fantasmagorice proiecte. Heliade însuși se îmbracă în togă pentru a relatiniza limba și e gata să schimbe vorbele când nu poate modifica, cum vrea, realitatea" (1980: 205). Precum aratam anterior, poetul retrasează liniile generale ale unui mister inițiatic în sens antic, în aceeași 
măsură în care lupta cu elementele într-un sens aproape concret. Ca paradigmă putem deduce că structura operei este una eteroclită având la bază un filon mistic. Opinia luii Al. Dima este una pertinentă: „Lumea (la Heliade Radulescu, n. n.) e văzută metafizic, dincolo de fenomenalitatea ei strictă, deci transcendent aici se îneacă în misticism, uneori de aspect talmudic și cabalistic" (1982: 36). Ioana Em. Petrescu afirmă că „structura operei lui Heliade- Rădulescu respectă structura deltei «istorice», al cărei arhetip ramâne Spiritul-Materia-Universul. Atunci când aspiră la valoarea de totalitate, opera se naște prin conjugarea a două limbaje (limbajul Spiritulu și cel al Materiei), cu o rezultanta de tip «Universul»" (Zaciu, Papahagi, Sasu, II, 1998: 499).

Filosofia lui Heliade Rădulescu are ca fundament un principiu clasic, și anume acela al armoniei lui Platon. În lucrarea Echilibru între antiteze, acesta afirma: „binele, cu un cuvânt, stă în echilibrul antitezelor și răul - în ruperea echilibrului antitezelor" (apud Tomoioaga, 1980: 231). Astfel putem compara antitetic următoarele secvențe textuale: Al păcii spirt e una cu-al dragostei, blândeții,/Al dragostei ş-al păcii într-una se unesc/Cu al inteligenței ş-al naltei frumuseţii,/Şi toate iar în Domnul şi cresc, şi viețuiesc.,, ...., , Oribilă durere de frunte îl cuprinde/Şi fruntea i se umflă, nu-1 mai încape loc;/În cugetu-i prin ură concepe şi s-aprinde,/Turbează apostatul, o spumă e, un foc.,"

Heliade Rădulescu împarte cognoscibilul în delte, din punct de vedere dialectic, astfel: delta supremă este reprezentată Dumnezeu-Tatal (Spiritul), Dumnezeu-Fiul (care poate fi Materia sau Universul) și Duhul Sfânt (Spiritul Verității). Radu Tomoioaga concluzionează: „În liniile sale esențiale, concepția filosofică a lui Eliade trebuie, de aceea, să fie considerată ca o varietate a dialecticii idealiste“. (1980: 236-237): ", În juru-Omnipotenţei miniştrii toţi sadună,/Atenţi în tot amorul, ascultă, se supun,/Văd toţi pe Fiul gloriei 1-a Patrelui său dreaptă/Şi cunoscut se face Cuvântul peste tot;/La vocea-i mundiferă creaţia aşteaptă/Şi laudă, mărire din arpele lor scot./Şi spirite, şi geniuri, şi minți ce nasc ştiință/ Întrec să se închine la Marele Cuvânt,/Prin el să se-ntregească în toată-a lor fiinţă. “

Creația lui Heliade din punct de vedere estetic frapează prin forța grotescului, a reinterpretării spirituale din care rezultă construcția dualistă prin intermediul modelului cosmologic al scriitorului alături de reperele descriptive antagonice receptate pe tot parcursul textului. 


\section{Bibilografie}

*** Biblia sau Sfânta Scriptură, traducere Dumitru Cornilescu, Ed. Casa Bibliei, București, 2012

*** Introducere în critica literara, Ed.. Tineretului, București, 1968

*** Hermeneutica ideii de literatura, Ed. Dacia, Cluj-Napoca, 1987

*** Sacrul. Despre elementul ira.ional din ideea divinului și despre relația lui cu Raționalul, trad. de Ioan Milea, Ed. Dacia, Cluj-Napoca, 1996

Rădulescu, I. Heliade, Scrieri alese. Text stabilit, glosar și bibliografie de Drimba, Vladimir, prefață și note finale de Constantin Maciuca, Ed. Tineretului, București, 1968

Rădulescu, I. Heliade, Studiu, antologie, tabel cronologic și bibliografie de Paul Cornea, Ed. Eminescu, București, 1980

Marino, Adrian, Biografia ideii de literatura, vol. al II-lea (Secolul Luminilor, secolul 19), Ed. Dacia, Cluj-Napoca, 1992

Negoițescu, I., Istoria literaturii române (1800-1945), Ed. Dacia, Cluj-Napoca, 2002

Negrici, Eugen, „Fericitul Heliade“. I. Heliade Radulescu. Studiu, antologie, tabel cronologic și bibliografie de Paul Cornea, Ed. Eminescu, București, 1980

Piru, Al., I. Eliade Rădulescu, Ed. Minerva, București, 1971

Simion, Eugen, Dimineața poeților, Ed. Cartea Românească, București, 1980

Tomoioaga, Radu, [„Concepția filozofica a lui I. Heliade Rădulescu“]. I. Heliade

Rădulescu. Studiu, antologie, tabel cronologic și bibliografie de Paul Cornea, Ed. Eminescu, București, 1980

Tugui, Grigore, Ion Heliade Radulescu îndrumatorul cultural și scriitorul, Ed. Minerva, București, 1984

Zaciu, Mircea; Papahagi, Marian; Sasu, Aurel (coordonatori), Dicționarul scriitorilor români, vol. al II-lea (D-L), Ed. Fundației Culturale Române, București, 1998 